\title{
Techniques For Measuring In Vitro Release From Semisolids
}

Joel L. Zatz, Ph.D. and Judith D. Segers, M.S.

Rutgers College of Pbarmacy

Piscataway, N7

-Dedicated to the memory of Loretta Kralo-

\section{Abstract}

The SUPAC-SS guidance, wbicb governs scale-up and post-approval changes for semisolids, requires in vitro release data in certain instances of change in the amount of an excipient, batch size or manufacturing equipment, process or site. The kinetics of diffusion of an active ingredient through a semisolid into a liquid sink (the receptor) are measured; an inert, porous membrane physically separates the two phases. Several commercial instruments, some of which incorporate automated transfer to an analytical instrument, are available.
The principal experimental decisions involve selection of temperature, membrane, receptor and timing of samples. These should be chosen to minimize undesired interactions and make diffusion through the semisolid rate-limiting, so that the intrinsic release is measured. Data treatment involves plotting the amount released against the square root of time and using the slope of the linear plot as an index. Release profiles may be altered by certain changes in manufacturing or formulation.

\section{Introduction}

In vitro release from semisolids may be visualized as a counterpart to tablet dissolution. In both techniques, the kinetics of drug release from a dosage form into a sink are determined. The receptor solution for a solid dosage unit may be simulated gastric fluid or a modification thereof, in recognition of the fact that a tablet or capsule administered orally spends some time in the stomach. Investigators may control experimental conditions to search for an in vitroin vivo correlation useful in further product development and testing.

Experiments of in vitro release from semisolids attempt to measure changes in important physical properties that may be related to topical bioavailability. However, measurement conditions do not usually mimic physiologic reality. In particular, the in vitro release setup does not include a membrane resembling the skin's stratum corneum, an essential determinant of skin penetration characteristics. Therefore, in vitro release is not a substitute for a clinical or bioavailability study. Instead, in vitro release provides information dependent upon certain physical attributes and should be considered an extension of other physical measurements, such as rheology and particle size.

Pharmaceutical manufacturers are currently not required to submit in vitro release data as part of an NDA or ANDA. The SUPAC-SS guidance, which governs scale-up and post-approval changes for non-sterile semisolids, requires release data in certain instances of change in the amount of an excipient, batch size or manufacturing equipment, process or site. (A copy of the guidance may be obtained by writing to the FDA Office of Training and Communications, Division of Communications Management, Drug Information Branch HFD-210, 5600 Fishers Lane, Rockville, MD 20857.
It can be downloaded from:

http://www.fda.gov/cder/guidance/index.htm.)

Lack of a significant difference in release, along with similar results for other tests, is an indication that such manufacturing changes have not materially altered product attributes.

The elements involved in measuring in vitro release from semisolids are:

a) the assay

b) the apparatus

c) the conditions (temperature, membrane, receptor, sample timing)

d) analysis of the data

Regardless of the apparatus used, the semisolid sample is supported by a thin membrane which physically separates it from a liquid (the receptor), into which the active diffuses. The receptor is sampled periodically and assayed to give a time-dependent release profile.

A reliable, reproducible, validated drug assay is essential in generating the data on which all conclusions will be based. High performance liquid chromatography (HPLC) is the method most commonly used, for both its accuracy and convenience, although gas chromatography and other techniques are possibilities in cases where an HPLC assay is not suitable. Assay sensitivity is an important issue if the rate of release is slow or the drug concentration very low, a common occurrence with many modern topical products.

From theoretical considerations, a plot of the amount released vs. the square root of time is expected to be linear after an initial lag period. The slope of the linear portion of the curve is an index of the release process and a logical 


\section{In Vitro Release from Semisolids. . . continued}

cowlaked frim thase a

pirameter lor comparing release characteristics, e.g., from two kors of a cream. The skope is calculated mom severit data points rather than a simgle neasurcinent, and should, therefore, be mare reproducible and reliable than any of the individual walues. As described betow, it is important to chonse measurement conditions that reveal the intrinsic relense characteristics and to select the correct section of the release curve for analysis.

\section{Technique: Apparatus and Procedures}

\section{A. Apparatus Designs - Revien}

Numerous designs of apparatus for studying diffision of ictive ingredients from semisolists hwe appeared in the literature, In genesA, these systems consist of a donor cell which holds the semisolid material, and a receptor cell or compartment which holds the chosen receptor medium and from which samples are withuirawn at regular intervals. The system may or may not include a membrane separaring the two phases, and means of stirring and controlling the temperature of the recoptor medium.,

A polyuethyl anethacrylate diffusion cell was described in 1964 , in which side-by-side compartments, one containing the ointment being studied and the other contaning the receptor flud, were separated by 2. vertical meinbrane and secured with bolts'. The entire cell was motnted on a shaker in a $3 y^{\circ} \mathrm{C}$. inculator for agitation and temperature control.

In 1968 a system was described where the gels being studied were supported in a Perri dish and placent in a $1,000-\mathrm{ml}$ leaker immersed in is $37^{\circ} \mathrm{C}$, water bath ${ }^{2}$. The receptor mediam was poured directly into the beaker and was stired with a multiple-blade laboratory stirer nsing a stirring blade as wide as the Petri dish. In this way up to six tests could be performed simultaneously.

A stadent laboratory experiment to sudy release from ointments used a one-ounce ointment jar as the donor compartment, over which a membrane was fistened with at ruber gisket and an open-top lid? The filled cell was then imerted with a damp and ring stand ane immersed in an evaporating dish containing the recejtor medium.

In a $19 \% 1$ report, Telon cells $3 \mathrm{~cm}$ wide and $0.4 \mathrm{~cm}$ deep werc used for studying release of fluocinonide from creamst. A menbrane coutl be secured ower the cream with a Tetlon rimg. The ecls were immersed in $200 \mathrm{ml}$ of receptor fluid, agitated with blakle stirrers, in beakers kept in $325^{\circ} \mathrm{C}$, water bath.

A flat, stainless steel cell $50 \mathrm{~mm}$ in diameter (capacity $5 \mathrm{ml}$ ) which lack it membrane and ointunent and was inmersed in a jacketed beaker of stirred receptor fluid was used to sturly the release of salicrlic acid from oinments. The cell material was chesen to minimize sorption of salievic acid.

Release of steroid drugs suspended in cintment bases was studied using a flat Teflon dish $5 \mathrm{~cm}$ in diameter". Ointment santes were spreal in a thin layer in the bottom of the dish, which was then invert-

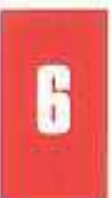
ed and floated on the surface of the receptor medium stirrest frem belose by a magnetic stirring bat,

Investigators scudying the release rate of hexylresorcinol from cintments removed the tij end of a $20-101$ polyethycene syringe, lilled the barrel with oinument, damper the plumger end to a USP dissolution apparatus, immersed the sintmene end in temperature-controlled recentor flud and wotated the sample at $50 \mathrm{rpm}^{7}$.

Artempes to study ding release from creams in direct contact with the recepter phase protaced a technigue wherely crean simples could be spread onto ; square stainless steel screen and inserted vervally into a ghas thin laver chomatography developing chamber filed with receptor medium stirred from the botrom with a mieromagnetic stirring bar"s

Modilications of the Sartorius Absorption Simulator, a derice designed to sumblate in viro gastromtestinal atosorption of drugs. have been appied to the study of drug diffusion from semisolids, 10 In these applications, the donor phase was held in a static chamber

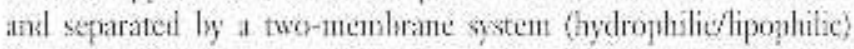
from the receptor medium which circulaced through a flow-through cell on the opposite side.

In 1987 a set of procedural guidelines for in wim percutaneous penetration studies was presented by the food and Drug fulministration and the American Association of Pharmacentical Scientists! For diffusion cell design, the authors recommend that:

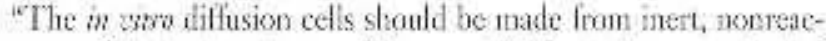
tive materials fsuch as glass, stainless sceel. Teflon. laetness flack of absorption to all components of the eell, including flow-thrsugh lines and the collection chambers themselves, should be denonsurates by experiment. It should also be shown that there is no loss of drug through is volatility during the permeations procedure. If volatility is a problem, a quantitative accounting of this must be made. The receptor medium should protide an effective sink for the penetrant. Ideally, it stould, at the same time, contain a minimum volume tes Gacilitate analysis becatase, in general, the more concentrated the drug in the collection medium, the easier its assay. The cell design should allow the receptor flusd so be well mixed and temperature conuolled:"

Although mumerous studies using modifications of the various sys rems described above hive been reported in recent years $12,13,44,15,16,17,18,19,20,21,22$, two design types have shown the most potential for use as standardized, compendial methods: vertical diffusion eells lor measurement of percutaneous atsorption (i.c.: Franz and modified Franz), which require use of a membrare when measuring drug release, anil immersion cells for use with the stantaril USP Dissolution Apparatus (t.e, the Vankel Enkancer Cell and the Hanson Oimment (ell), which may be ssed with or without a membrane. In 1989 the first report of the use of the Franz diffision cells as a potential quality control procedure to characterize the release behavior of topical dosage forms was published 23 . The Fnhancer Cell, incroducen in 1992 ${ }^{2}$, and the Hanson Oincment Cell are used in a standard LSP dissolution apparatus. The rematnder of the section will describe in detail the procedures for use of these two gopes of systems to deternine in wirn drug relese from semisolits.

\section{B. Procedures - Geveral Considerations}

Theoretical consislerations sriiling the choice of neabrane matetial and receptor composition and temperature are presented in 
Section III below. Membrane materials which have been used include nylon, cellulose, cellulose acetate, mixed cellulose ester, PVDF, PTFE, polypropylene, polysulfone, acrylic copolymer, and vinyl metricel. Membrane pore size is generally $0.45 \mu \mathrm{m}$ but can vary. Receptor medium temperatures typically used are 32,37 , or $25^{\circ} \mathrm{C}$.

Sampling with replacement of the receptor medium is done at regular intervals, either manually or by means of automation (see Section C. below). Appropriate sampling time intervals vary with the active component's solubility in the receptor medium and membrane permeability, and must be determined experimentally. Typical sampling intervals are $0.25,0.5,1,2,4,6$, and 8 hours, although a duration of greater than 24 hours may be necessary. A more detailed discussion of timing issues is given below in Section III.

Samples of receptor medium are then assayed for the active ingredient by the analytical method of choice; HPLC, UV spectroscopy, and gamma scintigraphy are typical. Data analysis primarily involves plotting the cumulative amount of drug released per unit area of sample vs. square root of time. The resulting plot should be linear in agreement with the equations of Higuchi ${ }^{25}, 26$ for diffusion-controlled release of drug present in suspension

$$
\begin{aligned}
& \mathrm{Q}=\left(2 \mathrm{C}_{n} \mathrm{C}_{5} \mathrm{D} \mathrm{t}\right)^{1 / 2}, \mathrm{C}_{\mathrm{s}} \ll \mathrm{C}_{n} \\
& \text { [Eq. 1] } \\
& \mathrm{Q}=2 \mathrm{C}_{0}(\mathrm{Dt} / \pi)^{1 / 2}
\end{aligned}
$$

where $\mathrm{Q}=$ amount of drug released per unit area of sample, $\mathrm{C}_{0}=$ initial concentration of drug in semisolid, $\mathrm{C}_{\mathrm{S}}=$ solubility of drug in semisolid matrix, D = diffusion coefficient of drug in semisolid, and $\mathrm{t}=$ elapsed time.

\section{Procedures - Apparatus Specifics and Automation}

A modified Franz diffusion cell (Crown Glass FDC-400) is illustrated in Figure 1. A similar cell is the Hanson 57-VC Vertical Diffusion Cell. The cell body consists of a jacketed glass receptor

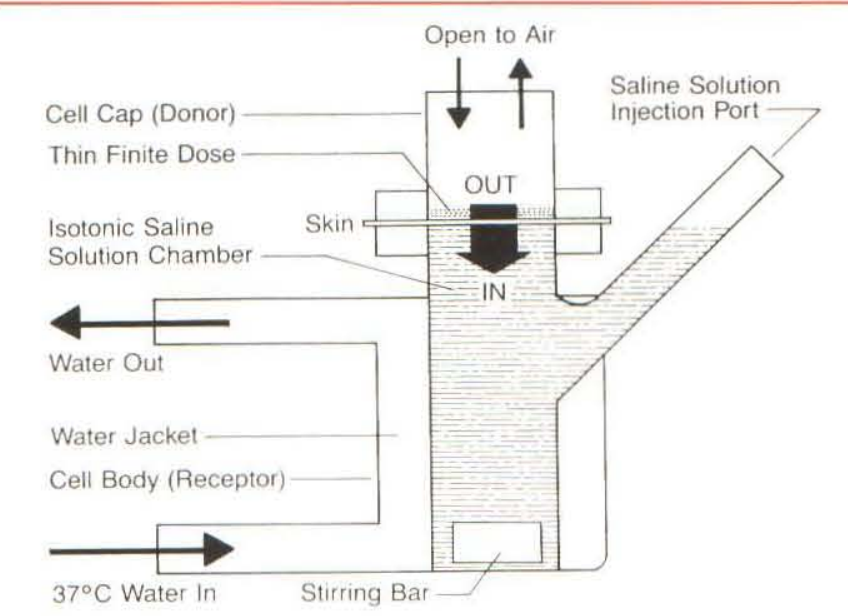

Figure 1. Modified franz diffusion cell (FDC-400). (Reprinted courtesy of Crown Glass Company, Inc.)

chamber, $12.5 \mathrm{ml}$ in volume (modified cells exist with slightly different receptor volumes) and a glass sampling port. The membrane is placed horizontally over the receptor chamber, the cell cap is applied over that, and the components are fastened together with a metal clamp. The test formulation can then be applied in a controlled amount with a syringe to the surface membrane through the top of the cell cap, which is open to the atmosphere unless sealed by the user. An alternative method of sample placement is to use a circular template having a diameter matching that of the cell opening. The template is used as a controlled-depth die into which the formulation may be evenly filled on a flat surface using a spatula and then inverted and placed on the membrane.

At the bottom of the receptor chamber a micro-magnetic stirrer is placed. The entire cell is positioned in a multiple-cell drive unit which drives the magnetic stirrer to agitate the receptor medium at a controlled rate. The jacketed portions of multiple cells are connected in series with tubing to a circulating temperature-controlled water bath.

Automated sampling for systems using this type of cell is available from Hanson Research as the Microette Topical and Transdermal Diffusion Cell System. Figure 2 is a schematic illustration of the automated system for one diffusion cell. At programmed time intervals,

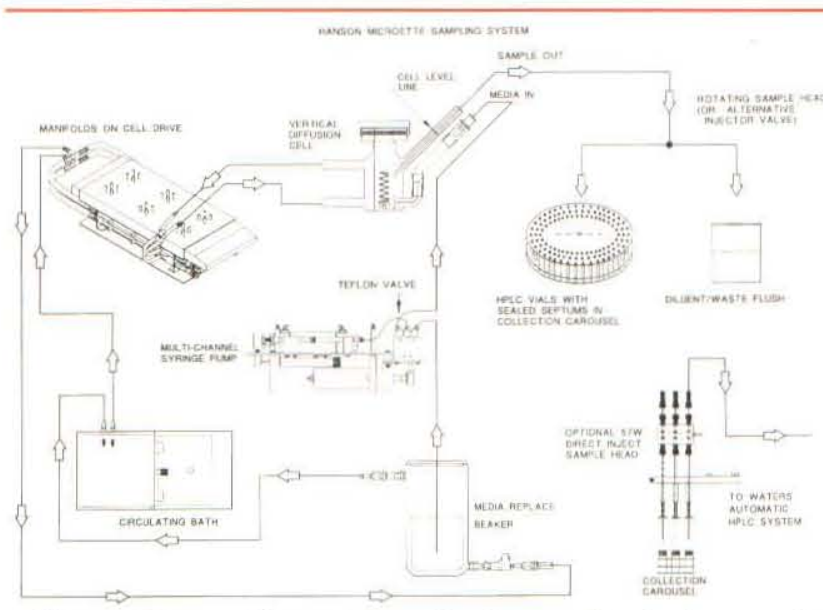

Figure 2. Hanson Microette Sampling System. (Reprinted courtesy of Hanson Researtb Corporation)

stirring of the receptor medium stops, a specified volume of fresh medium is injected via a syringe pump, and an equal volume of sample is simultaneously forced out of the chamber, through sample tubing and into precapped vials in a carousel. The stirring then begins again. A wash cycle cleans the sample lines just before the sampling occurs.

Complete automation of sampling and analysis has been accomplished by interfacing the Microette with Waters HPLC systems ${ }^{27,28}$. Sample withdrawal, transfer, and HPLC injection are coordinated via the Waters system controller, which also contains the HPLC methods programs for mobile phase composition and flow rate, column temperature, detector wavelength and injector sequence. Sample HPLC analysis takes place between sampling times while the dissolution test proceeds concurrently. Assay data acquisition and analysis are performed by the unit's networking computer system. A complete, fully automated system can be achieved by

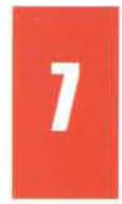

Dissolution Tecbnologies/FEBRUARY 1998 


\section{In Vitro Release from Semisolids. . ..continued}

linking the Microette with Direct Inject option to the Waters Automated Dissolution System.

Figar 3 shows an exploded view of the Wankel Enhancer Cell assembly and its placement in the modified $200-\mathrm{ml}$ vessel of a standard

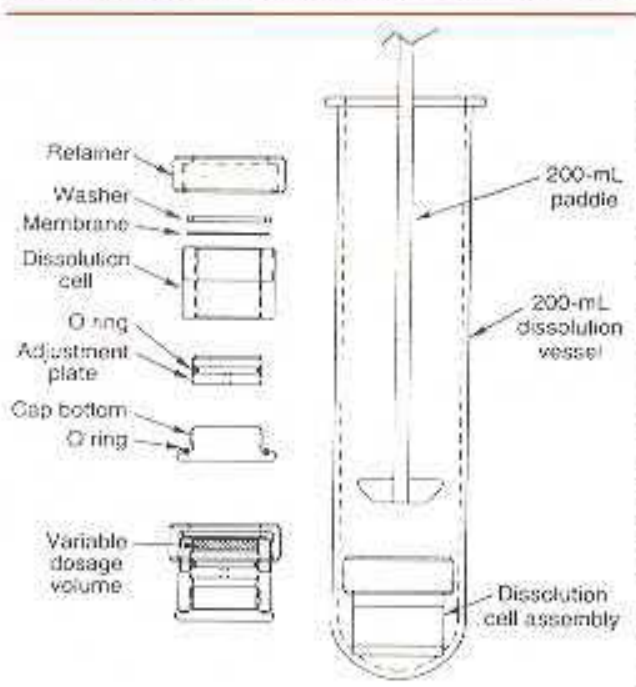

Figure 3. Enhancer Cell Asembly. Regringd ato-

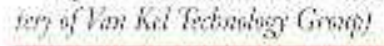

LSP Dissolution Apparatus. The cell, composed entrely of Teflon: consists of at adjustablecapacity sample reserooir, a washer for controlling area, and an oper scres-on cap to secure the washer and tmembrane orer the sample reservoir: This system can be used without a exposed surface membrane in place if desired. The varable dosage volume of the ceth loot is adjusteal using a special tool which inereases or decreases the depth of the resenoit. The test formulation is filled intos the owl reservor with the aikl of a spatula to obtain a smooth, exen surface and to minimine the possilbility of an air bubble between the sample surface and the membrane. Membranes imust be cut bo a diameter of approximately $30 \mathrm{~mm}$ and should slightly orerlap the top of the hoides when placed over the sample surfice. The sealing ring (waster) is then placed on top of the cell boty and the retainer is serewed on only until it just tonches the sealing ring. A special aligoment tool is then used to property position the sealing ring and seal the membrane rightly to the sample. The completed assembly is then placed in the bottom of the 2um-ml round-bottem dissolution sessel with the membrane/sumple strface facung up, ant the modified paddle is lowered to a pre-adjusted depth of $1 \mathrm{~cm}$ above the cell. An accurately measured volume of receptor medium which has been degassed and wanned it necessary to the desired temperature is anded to the resel, and the paddle motors are urmed on to begin the test.

The Hanson Ointment Cell is illustrated in Fignow + While it is similar in design and monation to the Enhmoer Cell, it possesses some notable differences. The dissolution flask is a $150 \mathrm{f}-\mathrm{ml}$ flat- bottom flask which ensures that the cell surlace will be level throughout the test and minimizes the dead volume surounding the Omtment Cell. The smple reservoir of the cell has fixed dimensions (standard is $15 \mathrm{~mm}$ orfice diameter and $3 \mathrm{~mm}$ dept; modifications are axailable) to ensure repentable sample wolmme. The applied membrame diameter of 25 mun accommodates many standard size filter discs.

Butomated sampling of these systens an be acomplished using the Hanson Dissocte, which is very similar

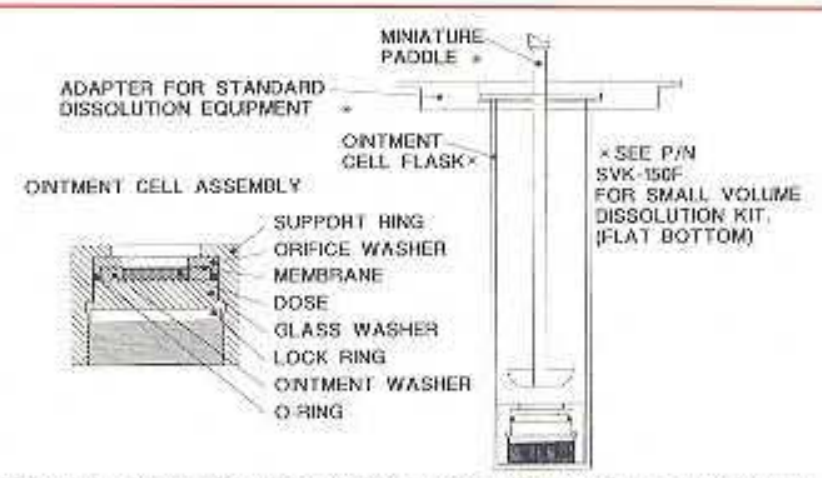

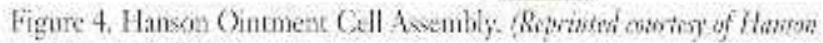
Resombli Garmation)

in operation to the Microette described abowe and which has been in widesprearl use for CSP dissolution testing for many gears. The Dissoette can also be interfaced with IIPLC or UV instruments and system computers for total atumation of testing as described for the Microette.

Automated saupling and UV assay of dissolution testing are axailable through Vankel is the NDS 2000 Automated Dissolution Analysis System. For automation of sampling and injection onto an IIPLC colum, the Vankel s020 Sample Collector/HPLC Autoinjector interfaces de dissolution tester with the HPL.C system via two main motales: a peristaltic pump Sample Collector and an lnjector Module consisting of a Rheodyne valwe ant a stringe pump.

\section{III.Setting Measurement Candititions}

The conditions st measurement indede temperature, choice of membrane and receptor, and the timing of sample collection. These depend on the type of product. Althought several protocols have been applicil ts a variety of products, it is milikely that a single protocol can accommodate every semisolid.

\section{d. Temperature}

Receptor remperature is genemally set to $32^{\circ} \mathrm{C}$ to approximate skin surface temperature ${ }^{29}$ An increase in termperature should result in an increase in the release rate, so some deviation from 32 le.g., 379 might be fustifable. ${ }^{30}$ On the other land, an exoessively ligh temperature that would melt a proluct or atherwise canse significant phesical changes should be avoided. In most cases, a tabonatory would decile on a single temperature and use it for all of their release studies.

\section{B. Membrane and receptor}

The membrine and receptor should generally be considered together, One reason is the need for compatibility between the two. In addition, the membranes used in release studics are porous and imbibe receptor fluid, which effectively becomes part of the membranc. Druy thus migrates through the semusolid to the membme surface and then through the liquid filled pores within the menbrane before reaching the builli of the receptor, where sampling ocours.

\section{Retoptor forichous}

The recentor collects the drug without limiting its transport, and must, thereforc: cxhibit goosi solvent properties to mainsain sink con- 
ditions. Drug solubility should be a minimum of ten times the highest expected concentration within the receptor. Matching the receptor to the external phase of the semisolid, where possible, limits solvent diffusion. So does choosing a receptor that is completely immiscible with the semisolid's external phase. The analysis is most conveniently accomplished by direct use of the receptor, e.g., by injection onto an HPLC column. The desire for a convenient analytical procedure may influence the choice of receptor. In addition, the receptor should be a highly fluid (non-viscous) material for reasons that are explained below.

\section{Membrane functions}

The membrane provides physical support to maintain a constant contact edge with the semisolid and prevent bulk transfer. It may be possible to work with rigid semisolids without using a membrane. The membrane should be inert toward both the receptor and the semisolid. Potential membranes can be screened for drug binding by passing a receptor liquid containing a low drug concentration, comparable to that which will be encountered in the experiment, through the membrane and assaying the filtrate to verify that no loss occurs.

Perfect wetting of the membrane by the receptor is necessary to ensure that air within the pores has been replaced completely by liquid. A guide to the surface character of the membrane material is a parameter called the critical surface tension. If the surface tension of the liquid (receptor) is equal to or less than the critical surface tension of the membrane surface, the contact angle is zero and wetting is perfect. Critical surface tension values for many substances may be found in standard references ${ }^{31}$ If the membrane floats when it is thrown into a beaker of receptor, wetting is poor. However, the converse is not necessarily true; a sinking membrane does not, in itself, guarantee perfect wetting.

\section{Membrane resistance to permeation}

In a release experiment, drug migration from semisolid to receptor occurs as a series of successive diffusional steps. Since the physical properties of the product itself are of interest in this measurement, diffusion through the semisolid must be the rate limiting step. It is, therefore, important that the membrane and receptor be highly permeable to the drug.

The membrane, together with an unstirred layer at its surface, offers finite resistance to diffusion. The effect of this resistance on the sensitivity of the release test to variation in several parameters was recently explored. ${ }^{32}$ Simulated release data were generated using a theoretical equation that took membrane resistance to permeation into account. Reasonable values for drug concentration $(10 \mathrm{mg} / \mathrm{ml})$, solubility $(0.2 \mathrm{gm} / \mathrm{ml})$ and diffusion coefficient $\left(1 \times 10^{-6} \mathrm{~cm}^{2} / \mathrm{s}\right)$ were assumed and different values for membrane permeability were modeled. The intrinsic release (release fully independent of the membrane) was the standard for comparison. With relatively high values of membrane permeability, the slope of the release plot (amount released vs. the square root of time) was essentially the same as the intrinsic release slope. At lower values of membrane permeability, the release slope became significantly smaller and the intercept with the abscissa, larger.

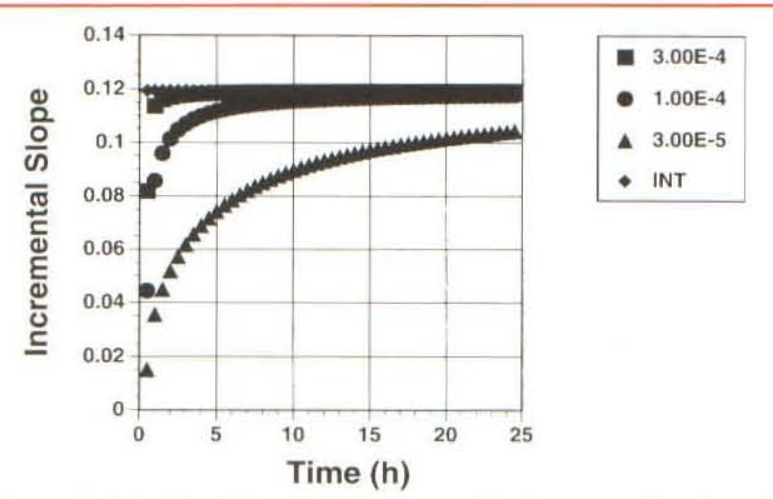

Figure 5. Simulated data sbowing rate of release as a function of time for various membrane permeability coefficient values. Model parameters are those utilized in reference 32.

The contribution of the membrane to the release profile is greater initially than after some time has elapsed. Over time, a diffusional layer that develops within the semisolid becomes rate controlling. Fig. 5 shows how the slope changes incrementally over time. Slope values increase with time, approaching a plateau value. The greater the membrane permeability coefficient, the shorter the time needed to reach the plateau. A practical consequence of this pattern is that early time points may have to be neglected in calculating the release slope.

A low membrane permeability also blunts the sensitivity of the release measurement to changes in important parameters. Figure 6 shows the effect of changes in the

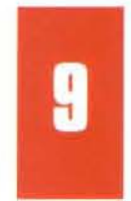




\section{In Vitro Release from Semisolids....continued}

diffusion coefficient within the semisolid (D) and P, the permeability coefficient of the membrane/stagnant layer on the release slope. An increase in $\mathrm{D}$ of $50 \%$ results in an increase in the release slope of approximately $22 \%$, provided that the membrane permeability was high. When it had a small value, the change in slope was much less.

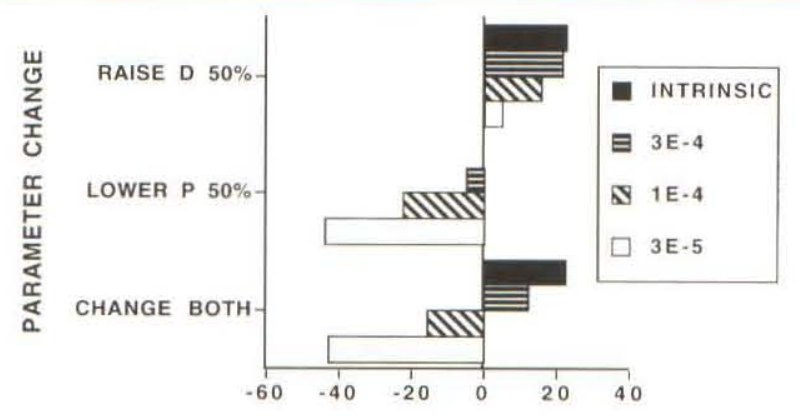

PERCENT SLOPE CHANGE

Figure 6. Effect of perturbation of two parameters, semisolid diffusion coefficient $(D)$ and membrane permeability coefficient $(P)$ on response of release measurements. Simulated data from reference 32.

Release slope should theoretically be unaffected by changes in the membrane. This is only true when membrane permeability is relatively high (Fig. 6). Furthermore, when there are changes in both D and $\mathrm{P}$, the response is dominated by shifts in P. Figure 6 shows that the membrane permeability determines the extent and direction of the change in slope when $\mathrm{D}$ is raised by $50 \%$ and $\mathrm{P}$ is simultaneously decreased by $50 \%$. When $\mathrm{P}$ is high to begin with, the change in slope primarily reflects the change in $\mathrm{D}$, a property of the semisolid. When the membrane permeability is small, the change in D is largely ignored and the slope decreases in value, despite the fact that D has been raised.

Clearly, it is desirable to keep the membrane permeability as high as possible. Some guidance in attaining this goal can be obtained from equation 3, which defines the membrane permeability coefficient, P.
$\mathrm{P} \approx \mathrm{D}_{\mathrm{M}} \mathrm{K} \Phi / \tau \mathrm{h}$
(Eq. 3)

In this equation, $D_{M}$ is the diffusion coefficient within the membrane, $\mathrm{K}$ the membrane/semisolid partition coefficient, $\Phi$ the membrane porosity, $\tau$ the membrane tortuosity and h the membrane thickness. One goal in membrane/receptor selection is to maximize the product $\mathrm{D}_{\mathrm{M}} \mathrm{K} \Phi$ and minimize $\tau$. Therefore, the membrane should be thin and highly porous (to make h small and $\Phi$ large, respectively). The receptor, which fills the pores, should be highly fluid and have a high drug solubility (to maximize $\mathrm{D}_{\mathrm{M}}$ and $\mathrm{K}$, respectively).

\section{Effect of the receptor on release slope}

Ideally, the receptor should act as an inert sink to collect drug as it diffuses from a semisolid. Theoretically, then, changing the composi-

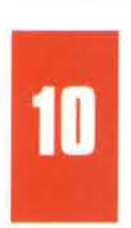
tion of the receptor should have no effect on release as long as both receptors maintain sink conditions. This is not always observed in practice. The receptor may modify the release rate by contributing to a diffusional resistance (as described in the previous section). Second- ly, back diffusion of the receptor might alter drug solubility in the semisolid. In an extreme example, ${ }^{33}$ octanol diffused from the receptor into a cream, dissolving it completely. Attempts to assay the semisolid for small amounts of receptor are likely to be fruitless. Additionally, accumulation of even low concentrations of a good drug solvent in the interfacial region is likely to have a disproportionally large effect on release.

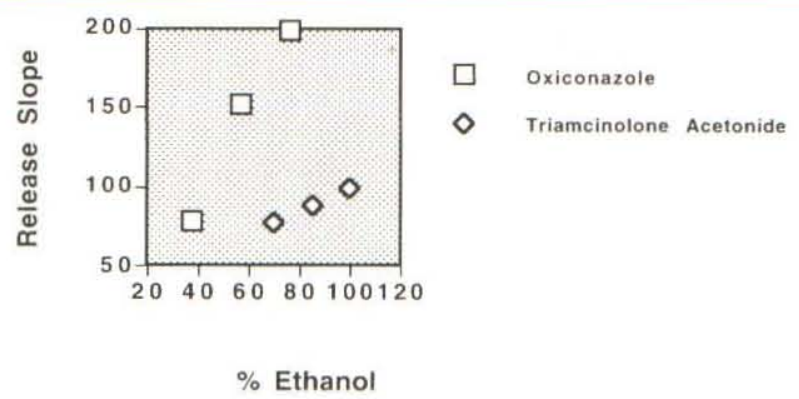

Figure 7. Effect of changes in etbanol concentration on measured release slope for two systems, a bydroalcobolic gel containing triamcinolone acetonide and a cream containing oxiconazole nitrate.

Figure 7 shows the effect of ethanol concentration in the receptor on release of two drugs from two very different systems. Triamcinolone was dissolved in a simple gel while oxiconazole nitrate was suspended in a cream base. In both cases, raising the ethanol concentration results in an increase in release slope. However the change in oxiconazole release is much larger, perhaps reflecting the importance of dissolution of some of this drug via back diffusion of ethanol.

In another dramatic example, various hydroalcoholic solutions were investigated as receptors to study release of betamethasone dipropionate from two creams which differed in composition. ${ }^{34}$ The less potent product was released more rapidly into $60 \%$ ethanol, but the order was reversed into $30 \%$ ethanol. As in the examples shown above, an increase in ethanol content in the receptor produced an increase in release slope. The effect of the difference in receptor ethanol content on the product containing suspended drug was significantly greater than the other cream. For the cream containing suspended drug (less potent) the ratio of release slopes, $60 \%$ ethanol receptor:30\% ethanol receptor, was 3.8; the corresponding ratio for the cream containing largely dissolved drug was 1.4.

From these examples, it is apparent that the release profile can be markedly influenced by the choice of receptor fluid. Comparisons of different formulations must be interpreted with caution. Validation studies are required to confirm the utility of any release protocol.

\section{Timing issues}

As was stated in the previous section, the early time values of amount released may not represent the situation in which diffusion through the semisolid is rate controlling. It may therefore be necessary to ignore one or more data points at the beginning of the experiment and use the remaining values to obtain the release slope. This situation is illustrated in Figure 8, line 2.

Line 1 in Figure 8 exhibits curvature at larger values of the square root of time. This pattern is anticipated when drug release exceeds 


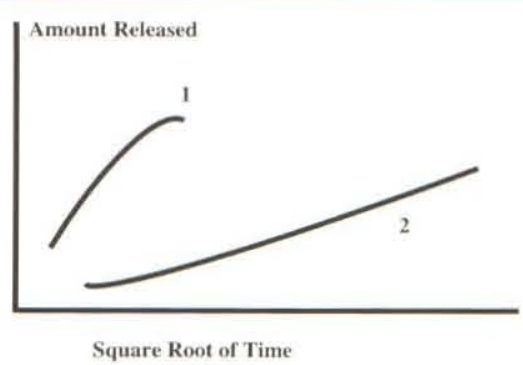

Figure 8. Anticipated release patterns for two systems. 1, fastreleasing gel; 2 , slow-releasing ointment.

approximately $35-45 \%$ of the semisolid's initial content. At this point, the assumptions underlying the equations which support a linear relation between amount released and the square root of time are no longer valid. If release is quite rapid (e.g., dissolved low molecular weight drugs in gel systems) curvature may be encountered in less than three hours.

There is thus a time window during which release experiments should be performed. Data should be collected at times after the influence of membrane and its associated stagnant layer disappears but before excessive drug depletion from the semisolid occurs. Because of significant differences in release patterns for dissolved vs. suspended drugs and creams or gels vs. ointments, it is probably not possible to develop a single protocol that applies to all semisolid products.

\section{Applitrations - Method Validation}

The core of validation of an in-vitro release method is the ability to detect changes in the release slope that occur when formulation composition is changed (active ingredient concentration, excipient composition and amount), when batches or sources of ingredients are changed, or when method of manufacture is changed. As noted above, the logical parameter for comparing release characteristics is the slope of the linear portion of the amount released vs, square root of time plot. Some recent examples of studies which show a relationship between the release slope and product or method variables will now be summarized.

A 1989 study of the release of hydrocortisone from creams used Franz diffusion cells and a variety of synthetic membranes ${ }^{23}$. Release profiles were compared by calculating steady state flux rates $\left(\mu \mathrm{g} / \mathrm{cm}^{2} / \mathrm{hr}\right)$ from the linear portion (last three data points) of the cumulative amount released per unit area vs. time curves. In experiments with two brands of cream, for a given formulation, flux values were not significantly different regardless of the membrane material (polysulfone, pure cellulose acetate, cellulose with wetting agent, and triton free cellulose), except for slightly slower flux values when a glass fiber filter was used. When the two brands of cream were tested under similar conditions, the flux values were found to be significantly different. When different batches of the same brand were compared, release profiles were found to be very reproducible for both brands with no significant differences in flux values. In a subsequent communication 35 , it was proposed that "for the purpose of a batch-to-batch test, or a comparison between innovator and generic products, the slopes (of the amount released per unit area vs. square root of time plots) would be meaningful and accurate, and would make efficient use of all the experimentally collected data." This commentary also cautioned against extrapolation of results of these in vitro experiments to the in vivo situation. In 1991, the methodology developed for hydrocortisone creams was applied to determine release from lotions and ointments ${ }^{27}$. In order to obtain detectable levels of hydrocortisone in the receptor medium from the ointment formulations, it was necessary to pre-treat a hydrophilic membrane (cellulose acetate) with isopropyl myristate to impart mixed hydrophilic and lipophilic properties to the membrane and thus enhance release of hydrocortisone from the ointment. The study found similar release slopes from cream and lotion but significantly lower release slope from the ointment, which reflects the influence of the viscosity on the diffusion coefficient of the drug between the vehicle and the receptor phase. The authors pointed out that the pharmacological response is actually greater from the ointment due to development of skin hydration, and cautioned that "release characteristics should not be compared across types of formulations, such as creams, ointments and lotions. All comparisons should be done only with similar formulations."

A comparison of the release behavior of triethanolamine salicylate from commonly used ointment bases with various additives (penetration enhancers), and from two commercial products, used a modified Franz cell apparatus ${ }^{36}$. These studies showed significantly higher release from the experimental formulations than from the commercial formulations. Apparent viscosity profiles of the formulations were obtained but showed no clear correlation with drug release.

An evaluation of the release of griseofulvin from gels used Franz diffusion cells $s^{37}$. Significant differences in release slopes were found among gels prepared using different solvents and different drug concentrations, with differences in release slopes directly proportional to differences in drug concentrations for a given gel formulation.

In 1992, in vitro release of betamethasone valerate from two brands of cream was measured using Franz cells and compared to in vivo skin blanching characteristics ${ }^{38}$. It was found that the release slope was significantly greater from the higher blanching formulation, but the authors cautioned that while "the correlation obtained between the in vitro release and in vivo performance adds strength and validity to the in vitro test...it should be emphasized that the release test is strictly a quality control test to assure lot-to-lot uniformity and should not be used to predict bioactivity."

An in vitro release method for retinoic acid creams using modified Franz cells was developed and validated ${ }^{39}$. Formulation physicochemical factors (drug concentration, internal phase droplet size distribution, viscosity, and composition of emulsion internal and external phases) were varied and compared for influence on drug release from creams. Viscosity measurements were also obtained but showed no correlation with release slopes. The method was shown to be sensitive to formulation changes, with oil phase volume ratio showing the most significant effect on drug release slope. Inter- and intra-

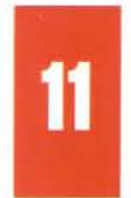

DissolutionTechnologies/FEBRUARY 1998 


\section{In Vitro Release from Semisolids....eontinued}

batch variation was found to be low with very reproducible release slopes.

An in vitro release method for terconazole cream formulations using modified Franz cells was developed and validated ${ }^{40}$. The method was able to detect differences in drug loading, drug particle size, and formulating technique. Release profiles were obtained for eleven lots of the commercial cream product, and lot-to-lot variability was found to be low.

Diffusion of hydrocortisone from a commercial ointment formulation using Franz diffusion cells and VanKel Enhancer (immersion-dissolution type) cells was measured and compared ${ }^{14}$. The authors reported higher cumulative release as well as greater durability and ease of use for the Enhancer cell vs. the Franz cell. However, the data were presented as plots of cumulative amount released vs. time, and the "cumulative" amount released often actually decreased from one time point to the next. No slope calculations or other mathematical treatment of the data were presented and the conclusions were drawn solely based on the visual appearance of the amount released vs. time plots.

Another study compared release profiles from gels of differing concentrations of triamcinolone acetonide using Franz diffusion cells and dissolution cells ${ }^{41}$. In these experiments the release was found to be rapid and linear with square root of time, with release slopes varying in direct proportion to drug concentration in the gels. While both types of apparatus produced similar results, release slopes were slightly higher and diffusion coefficients more consistent with the dissolution cells. The studies also showed a decrease in release slope proportional to an increase in membrane thickness.

In measuring in vitro release of betamethasone dipropionate from petrolatum ointments using Franz cells ${ }^{42}$ it was possible to distinguish between two different formulations containing the same concentration of the drug. Methods used to obtain detectable, quantifiable levels of drug in the receptor medium were also investigated.

Release of phenol from petrolatum ointments was studied using the dissolution cell system ${ }^{30}$. Release characteristics were compared to evaluate sensitivity of the method to changes in test parameters (stirring speed, membrane type), formulation (active ingredient and excipient levels), and manufacturing procedure, and to identify a correlation between drug release and ointment rheology. Release slopes were shown to be the same whether diffusion was through a nylon membrane, a cellulose acetate membrane, or no membrane at all; however, standard deviations were greatly reduced when a membrane was used. At various stirring speeds $(75,125$, and $200 \mathrm{rpm})$, release slopes were shown to be the same; however, standard deviations were significantly greater at $75 \mathrm{rpm}$. Release slopes varied proportionately with drug concentration and changed significantly when excipient levels and method of manufacture were varied. Preliminary rheologic characterization suggested a possible correlation between release

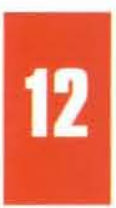

behavior and certain viscoelastic parameters. In general, as the ointment viscosity or magnitude of the viscous component of the viscoelastic material ("loss tangent") increased, release slope correspondingly decreased.

APPENDIX - Equipment Suppliers

Crown Glass Company, Inc.

990 Evergreen Drive

Somerville, NJ 08876

(908) 526-3115

Hanson Research Corporation

9810 Variel Avenue

Chatsworth CA 91311

(800) $821-8165$

VanKel Technology Group

13000 Weston Parkway

Cary NC 27513-2228

(800) $229-1108$

\section{References}

1. N.K. Patel and N.E. Foss, "Interaction of Some Pharmaceuticals with Macromolecules 1," J. Pbarm. Sci. 53, 94- (1964).

2. B.I. Poulsen, E. Young, V. Coquilla, and M. Katz,"Effect of Topical Vehicle Composition on the In Vitro Release of Fluocinolone Acetonide and its Acetate Ester," 7. Pharm. Sci. 57, 928-933 (1968).

3. F. Billups and N.K. Patel, "Experiments in Physical Pharmacy. V. In Vitro Release of Medicament From Ointment Bases," Am. 7. Pharmaceutical. Edtuation, 34, 190)-196 (1970).

4. J. Ostrenga, J. Haleblian, B. Poulsen, B. Ferrell, N. Mueller, and S. Shastri, "Vehicle Design for a New Topical Steroid, Fluocinonide," 7. Investigative Dermatology 56, 392-399 (1971).

5. F. Bottari, G. DeColo, E. Nannipieri, M.F. Saettone, and M.F. Serafini, "Influence of Drug Concentration on In Vitro Release of Salicylic Acid from Ointment Bases,” 7. Pbarm. Sci. 63, 1779-1783 (1974).

6. Z.T. Chowhan and R. Pritchard, "Release of Corticoids from Oleaginous Ointment Bases Containing Drug in Suspension," f. Pbarm. Sci. $64,754-759(1975)$.

7. K. Iga, A. Hussain, and T. Kashihara, "Effect of Complex Formation between 4-Hexvlresorcinol and Ethyl Myristate on Release Rate of 4Hexylresorcinol from Petrolatum Base," 7. Pharm. Sci. 70, 939-943 (1981)

8. R.J. Behme, T.T. Kensler, and D. Brooke, "A New Technique for Determining In Vitro Release Rates of Drugs From Creams," 7. Pharm. Sci. 71, 1303-1305 (1982).

9. M. Otagiri, T. Fujimaga, A. Sakai, and K. Uekama, "Effects of $\beta$ - and $\gamma$-Cyclodextrins on Release of Betamethasone from Ointment Bases," Chem Pharm. Bull. 32, 2401-2405 (1984).

10. N.A. Armstrong, H.A. Griffiths, and K.C. James, "An In Vitro Model to Simulate Drug Release from Oily Media," Int. J. Pbarm. 41, 115119 (1988).

11. J.P. Skelly, V.P. Shah, H.I. Maibach, R.H. Guy, R.C. Wester, G. Flynn, and A. Yacobi, "FDA and AAPS Report of the Workshop on Principles and Practices of In Vitro Percutaneous Penetration Studies: Relevance to Bioavailability and Bioequivalence," Pharm. Res. 4, 265-267 (1987).

12. H.L.G.M. Tiemessen, H.E. Bodda, C. van Mourik, and H.E. Junginger, "In vitro Drug Release from Liquid Crystalline Creams; Cream Structure Dependence," Progr: Colloid \&o Polymer Sci. 77, 131-135 (1988).

13. B. Martin, O. Watts, B. Shroot, and J.C. Jamoulle, "A New Diffusion Cell- an Automated Method for Measuring the Pharmaceutical Availability of Topical Dosage Forms," Int. 7. Pharm. 49, 63-68 (1989).

14. L. Niemi and P. Kahela, "Effect of Water Content and Type of Emulgator on the Release of Hydrocortisone from O/W Creams," Acta Pharm. Nordica 1, 23-30, (1989).

15. S.C. Chi and H.W. Jun, "Release Rates of Ketoprofen from 
Poloxamer Gels in a Membraneless Diffusion Cell," J. Pharm. Sci.80, 280283 (1991).

16. M.K. Youssef, E.E. Zein El-Din and M.A. Fouda, "Preformulation Studies on Rifampicin Ointments Part II. Comparative Evaluation of the Various Release Techniques," Drug Dev. Ind. Pharm. 17, 317-323 (1991).

17. M.D. DiBiase and C.T. Rhodes, "Investigations of Epidermal Growth Factor in Semisolid Formulations," Pbarm. Acta Helv. 66, 165-169 (1991).

18. A. Rolland, G. Demichelis, J.C. Jamoulle, and B. Shroot, "Influence of Formulation, Receptor Fluid, and Occlusion on in Vitro Drug Release from Topical Dosage Forms, Using an Automated Flow-Through Diffusion Cell," Pharm. Res. 9, 82-86 (1992).

19. M. Foldvari, B. Jarvis, and C.J.N. Oguejiofor, "Topical Dosage Form of Liposomal Tetracaine: Effect of Additives on the in Vitro Release and in Vivo efficacy," 7. Controlled Release 27, 193-205 (1993).

20. S.C. Chattaraj and I. Kanfer, "Release of Acyclovir from Semi-Solid Dosage Forms: a Semi-Automated Procedure Using a Simple Plexiglass

Flow-Through Cell," Int. 7. Pharm. 125, 215-222 (1995).

21. S.C. Chattaraj, J. Swarbrick, and I. Kanfer, "A Simple Diffusion Cell to Monitor Drug Release from Semi-Solid Dosage Forms," Int. 7. Pbarm. 120, 119-124 (1995)

22. S.C. Chattaraj and I. Kanfer, “'The Insertion Cell': a Novel Approach to Monitor Drug Release from Semi-Solid Dosage Forms," Int. 7 . Pharm. 133, 59-63 (1996).

23. V.P. Shah, J. Elkins, S.Y. Lam, and J.P. Skelly, "Determination of in Vitro Drug Release from Hydrocortisone Creams," Imt. 7. Pharm. 53, 53-59 (1989).

24. P.P. Sanghvi and C.C. Collins, "Comparison of Diffusion Studies of Hydrocortisone between the Franz Cell and the Enhancer Cell", Drug Dev. Ind. Pharm., 19, 1573-1585 (1903).
25. T. Higuchi, "Rate of Release of Medicaments from Ointment Bases Containing Drugs in Suspension,” 7. Pharm. Sci. 50, 874-875 (1961).

26. W. Higuchi, "Analysis of Data on the Medicament Release from Ointments," 7. Pbarm. Sca. 51, 802-804 (1962).

27. V.P. Shah, J. Elkins, J. Hanus, C. Noorizadeh, and J.P. Skelly, "In Vitro Release of Hydrocortisone from Topical Preparations and Automated Procedure," Pharm. Res. 8, 55-59 (1991).

28. J.B. Li and P.C. Rahn, "Automated Dissolution Testing of Topical Drug Formulatioins Using Franz Cells and HPLC. Analysis," Pharm. Tech. $17(7), 44-54(1993)$.

29.V. P. Shah, J. S. Elkins and R. L. Williams, In vitro drug release measurement for topical glucocorticoid creams, Pharmacopoeial Forrm, 19, 5048-5056 (1993).

30. J. D. Segers, J. L. Zatz and V. P. Shah, In vitro release of phenol from ointment formulation, Pharm. Tech., 21 (1), 70-81 (1997).

31. A. W. Adamson, Physical Chemistry of Surfaces, 5 th Ed., Wiley Interscience, NY, 1990, pp. 398-400.

32. J. L. Zatz, "Drug release from semisolids: effect of membrane permeability on sensitivity to product parameters," Pharm. Res., 12, 787-789 (1995).

33. A. G. Demichelis, J.-C. Jamoulle and B. Shroot, "Influence of formulation, receptor fluid and occlusion, on in vitro drug release from topical dosage forms, using an automated flow-through diffusion cell, Pbarm. Res., 9, 82-86 (1992).

34. J. S. Elkins and V. P. Shah, Role of receptor media in in vitro release See References...continued on page 17 
References...contimued fiom page 13.

studies of creams, Pharm. Res., 11, S-46 (1994).

35. R.H. Guy, J.H. Hadgraft, "On the Determination of Drug Release Rates from Topical Dosage Forms," Int. 7. Pharm. 60, RI-R3 (1990).

36. A. Babar, P.J. Chickhale, and F.M. Plakogiannis, "Assessment of

Triethanolamine Salicylate Release from the Dermatological Bases and the

Commercial Products," Pbarm. Acta Helv. 66, 322-328 (1991).

37. M.D. Vlachou, D.M. Rekkas, P.P. Dallas, and N.H. Choulis,

"Development and In Vitro Evaluation of Griseofulvin Gels Using Franz Diffusion Cells," Int. 7. Pharm. 82, 47-52 (1992).

38. V.P. Shah, J. Elkins, and J.P. Skelly, "Relationship Between In Vivo Skin Blanching and In Vitro Release Rate for Betamethasone Valerate Creams," 7. Pharm. Sci. 81, 104-106 (1992).

39. S.C. Kundu, A.D. Cameron, N.M. Meltzer and T.W. Quick, "Development and Validation of Method for Determination of In Vitro
Release of Retinoic Acid from Creams," Drug Dev. Ind. Pharm. 19, 425438 (1993).

40. M. Corbo, T.W. Schultz, G.K. Wong and G.A. Van Buskirk, "Development and Validation of In Vitro Release Testing Methods for Semisolid Formulations," Pharm. Tech. 17 (9), 112-128 (1993).

41. H.M. Fares and J.L. Zatz, "Measurement of Drug Release from Topical Gels Using Two Types of Apparatus," Pbarm. Tech. 19 (1), 52-58 (1995).

42. J.L. Zatz, J. Varsano, and V.P. Shah, "In Vitro Release of Betamethasone Dipropionate from Petrolatum-Based Ointments," Pharm. Dez. Tech. 1, 293-298 (1996). 